\title{
Construction and Reformation of Fishing Gear and Fishing Method
}

\author{
Hai-long XU ${ }^{1,2,3}$, Guo-xia ZHU 1,2,3 ${\text { Li LI }{ }^{1} \text {, Qing-xia KONG }}^{1,2,3}$ \\ Dong-qing $\mathrm{BAI}^{1,2,3, *}$ \\ ${ }^{1}$ College of Fishery, Tianjin Agricultural University, Tianjin, China \\ ${ }^{2}$ National Demonstration Center for Experimental Aqua-ecology and Aquaculture Education \\ Tianjin Agriculture University, Tianjin, China \\ ${ }^{3}$ Tianjin Key Laboratory of Aqua-ecology and Aquaculture, Tianjin, China \\ ${ }^{*}$ Corresponding author
}

Keywords: Fishing Gear and Fishing Method; Experimental Teaching; Construction.

\begin{abstract}
Located the talent cultivating and the educational objective, the experimental teaching contents of fishing gear and fishing method were explored and constructed. The educational objective was redefined, the educational contents were integrated and updated, the teaching material was compiled, and the way of examination was rationalized.
\end{abstract}

\section{Introduction}

Marine fishery is one of main marine industries in China, and occupies an important place in civil economy. In the middle and late 20th century, marine fisheries resources of China were exploited on a large scale, fishing production has been ranked the first all over the world since 1989, but most the economic fish resources have been seriously damaged. In order to ensure the sustainable development of China marine fishing industry, China government signed the $<$ United Nations Convention on the Law of the Sea > in 1996 and began to implement the "Zero Growth" plan of marine fishing production in 1999; At the same time, the marine fishery resources and the fishery waters environment in other sea areas all over the world are also generally damaged in varying degrees. Based on the status in lacking of global fishery resources, the development of marine fisheries has changed from free fishing to strict management, the types of fishing gear and sizes of net mesh, what are the main exploited tools of marine fishery resources, are strictly restricted [1].

Talents training and education for marine fisheries in China has more than one hundred years of history, it has gone through a series of evolution included major name, study year and major integration, and has developed into marine fishery science and technology major which awarded engineering or agriculture degree with four-year school education system, trained compound talents of high technology who can engage in survey, assessment and management of marine fishery resources, development and research of marine fishery resources fishing technology, monitoring and protection of fishery water environment and Fishery administration management [2]. At present, 10 colleges and universities had established this major, included Shanghai Ocean University, Ocean University of China, Dalian Ocean University, Zhejiang Ocean College, Jimei University, Tianjin Agricultural University, Guangdong Ocean University, Hebei Agricultural University, Yantai University, Qiongzhou College (Tropical Ocean University).

Fishing gear and Fishing method is one of the prominent professional course in marine fishery science and technology major, and the goal of the course is to impart related knowledge and skills in fishing gear and fishing method. In order to achieve the teaching effectiveness better, at the development beginning of course of Fishing gear and Fishing method which was restricted by the construction of teaching staff in marine fishery science and technology major of Tianjin Agricultural University, the content of course not only included the traditional course content of fishing gear and fishery method, but also included part of fishing gear materials and technology, fishing gear theory and design, and mechanics of fishing gear. 


\section{Goal of Course Construction}

Based on the content and characteristics of course, the goal of this curriculum are to select reasonable fishing gear materials for fishery production and use correct skills to assemble fishing gear, to enhance fishing efficiency of fishing gear by means of extending application period for fishing gear and to train students' abilities and skills in fishing gear design, fabrication and assembly by studying the types and characteristics of fishing gear materials, assembly technological and calculation of fishing gear. The trained students can carry out research about fishing technology based on the quantity and distribution characteristics of fishing targets species and fishing ground environment (sediment, landform, hydrology, meteorology etc.). And the teaching activities were implemented to train students of marine fishery science and technology major who mastered the fishing skills and manipulative ability and let students grasped the knowledge and abilities in technology of fish detection, fish collection, fishing gear assembly process and fishing operation [3].

\section{Construction of Teaching Contents}

In order to improve the comprehensive quality of trained undergraduates, the experimental teaching contents of fishing gear and fishery method are determined based on the objectives of training talents in marine fishery science and technology major, the current development trend of fishing gear and fishing method, experience from many other brothers colleges and universities and discussions between the relevant department staff. There are seven parts in the experimental teaching contents of fishing gear and fishery method, and they are identification of fiber materials for fishing, the twisting index of twisted netting twine, knitting technology of knot, knowledge of fishing gears and accessories, weaving net, addition and subtraction of mesh, cutting net, etc. Among of them, twisting index of twisted netting twine (recognizing single twisted netting twine, folded twisted netting twine and cable twisted netting twine; discern the twist direction; measuring diameter and twist of twisted netting twine), knowledge of nets, fishing gears and accessories (structural characteristics of knot netting (flat knot, mesh knot), knotting method, structural characteristics of knotless netting (insertion, braiding, twisting), structure and assembly of fishing gear (trammel net, falling net and brail), operation method of fishing gear, type of sinker and binding process), and weaving net (weaving with beginning of half mesh) were confirmatory experiments; and identification of fiber materials for fishing (judging material kind according to the morphology, density, characteristics of synthetic fibers closed to fire, combustion and after leaving fire), knitting technology of knot (methods for several kinds of knots (e.g. fisherman knot, pile tie, packing knot, etc.) for fishing), addition and subtraction of mesh (the basic form, structure and calculation of addition mesh and reduction mesh, the implementation method of incorporation and losing ), and nets cutting (calculation and implementation of centrally symmetric tailoring) were comprehensive experiments. According to the difficulty and workload of the experimental project, the corresponding class hours were set, and the teaching hours were extended for individual students in the actual teaching process.

\section{Teaching Materials Selection}

The selection of teaching materials or reference books has a direct impact on learning of students and teaching of teachers. For students majoring in marine fishery science and technology, the main purpose of carrying out experimental teaching of fishing gear and fishery method is to train students to develop designing and fabricating of fishing gear combined with professional knowledge, assembly process skills and manipulative ability. Despite the continuous development of teaching materials for fishing gear materials and technology, fishing gear and fishing method or marine fishery technology, the experimental teaching materials have been lacking. Former teaching was carried out with experimental guidance attached to fishing gear materials and technology, however on the one hand, the experimental guidance content is outmoded and is lack of new research results, on the other hand, it is difficult to integrate with the characteristics of talents training. In order to 
achieve teaching objectives better and highlight the application of teaching content, an experimental teaching manual of fishing gear and fishery method for students majoring in marine fishery science and technology of Tianjin Agricultural University was developed for the experimental project, it retained the classic twisting index that has been used to now, knowledge of fishing gears and accessories, three verification projects of weaving nets and addition mesh and subtraction mesh, two comprehensive projects of fishnet cutting and two experimental projects of identification in amalgamation of new research results and improved fibril materials for fishing and knitting skill of knot.

\section{Examination Forms}

The key assessments in experimental teaching of fishing gear and fishery method are operational ability and mastery of relevant skills and knowledge for training students, the simple forms in traditional experimental report and final examination paper were unable to meet the assessment demand of the course, the complete results of the experiment can fully reflect the characteristics of the comprehensive and practical of the courses [4], but it was lack of examination of basic theoretical knowledge, therefore, the examination method of this course changed into the pattern which combined class achievement in experimental class (students' performance in class, the answers to questions in basic theoretical knowledge, the standard degree of operation during experimental process and completion of experimental contents in interactive teaching process), grade of experimental report (understanding of the purpose of experiment teaching, mastering of content in experimental courses) and final examination scores (grasping for knowledge and skills, grasping for structure of knots and nets and so on). Flexibility and diversity of assessment methods contributed to promote the results of classroom teaching process, and strengthen students learning level in usually, on the other hand, which have a favorable promotional effect on comprehensive quality, manipulative ability and innovative ability of trained students.

\section{Summary}

The 21 st century is the century of ocean, marine fisheries as an important traditional industry is facing new opportunities and challenges with the rapid development of the marine economy. The cultivation of talents in marine fishery science and technology major has an inescapable responsibility because of the necessary to implement the protective exploitation and sustainable development of fishery resources through developing scientific fishing gear design, fabrication and assembly no matter in offshore fisheries or in pelagic fisheries with rapid development of marine economic.

This study carried out experimental teaching reform by means of further clarifying the goal of the experiment teaching of fishing gear and fishing method in marine fishery science and technology major, updating experimental teaching contents, making an experimental handout, and diversifying comprehensive examination. All above mentioned actions, which provided a possible solution to realize the protective exploitation and sustainable development of fishery resources combined with the theoretical knowledge of fishing gear and fishery method.

\section{Acknowledgement}

This research was financially supported by the important project for the education reform of Tianjin Agricultural University (2017-B-02).

\section{References}

[1] Hailong Xu, Feiyue Li, Li Li, et al. Preliminary exploration in construction of experimental teaching system [J]. Science and Technology Innovation Herald, 2013 (20): 155-156.

[2] Manchang Sun, Hong Yang, Liuxiong Xu. The teaching reform and practice of curricula for 
marine fishery science and technology major [J]. Higher Agricultural Education, 2004 (9): 52-54.

[3] Weiguo Qian, Xuchang Ye, Jian Zhang. Construction and exploration in group of fishing gear and fishing law course [J]. Intelligence, 2017 (15): 161, 224.

[4] Li Li, Hailong Xu, Dongqing Bai. Construction of innovation mode of teaching reform in marine fishery science and technology specialty major [J]. Education and Vocation, 2015 (16): 8991. 